\title{
Stability of one-stage adjustable suture for the correction of horizontal strabismus
}

\author{
P C CHOW
}

From the Department of Ophthalmology, Yaumatei Jockey Club Polyclinic, Kowloon, Hong Kong

SUMMARY One-stage adjustable suture for strabismus correction, with the whole operation done under topical anaesthesia and adjustment done on the table, was performed on 45 consecutive patients. The stability of the post-adjustment result was studied by comparing the post-adjustment deviation on the operating table to that at six weeks and three months after operation. The stability was comparable to that following the usual two-stage adjustable suture. The original angle of deviation and the fusion status were found to have no bearing on the stability of the procedure.

The usual adjustable suture for the correction of strabismus, described by many authors, ${ }^{1-10}$ is a twostage procedure in which the recession with or without resection is performed as one operation and the adjustment is performed as a second procedure some hours later. A procedure involving multiple stages of adjustment has also been reported by Howard and Smith."

In this study the operation has been modified to a one-stage procedure. The operation is performed under topical anaesthesia and the adjustment done on the operating table. A similar procedure has been described by Thornson et al. ${ }^{12}$ and Fells. ${ }^{13}$ The stability of the procedure is studied.

\section{Material and methods}

This operation has been performed since November 1986. It was offered to all adult patients and some selected children. They constituted a heterogeneous group of varied diagnoses and deviations. Forty-five consecutive patients followed up for three months after the operation were included in this study. There were 21 males and 24 females, ranging from 8 to 41 years old, average $21 \cdot 8$. There were 33 cases of exotropia and 12 of esotropia. The range of deviation was -20 prism dioptres (PD) to $-80 \mathrm{PD}$ with a mean of $-46 \cdot 8 \mathrm{PD}$ for exotropia and $+20 \mathrm{PD}$ to $+70 \mathrm{PD}$ with a mean of +43.6 PD for estotropia. There were six patients with previous strabismus surgery, eight

Correspondence to Dr P C Chow, Room 1916, Argyle Centre 1. 688 Nathan Road, Mong Kok, Kowloon, Hong Kong. with other eye operations (for example, cataract extraction), one patient with Duane's syndrome, and one with third nerve palsy. The details of each case will not be discussed in this report.

All the patients had a preoperative ocular examination and orthoptic assessment, including angle of deviation for near $(1 / 3 \mathrm{~m})$ and distant vision $(6 \mathrm{~m})$ with and without correction, measured by prism cover test; and fusional ranges measured by prism or major amblyoscope and stereopsis.

Premedication consisted of Neosporin (neomycin, gramicidin, and polymyxin B) eyedrops and Novesin (oxybuprocaine) $1 \mathrm{ml}$ into the eye to be operated upon one hour before operation. All operations were performed by the same surgeon using the same procedure.

Two fixation sutures with 5-0 silk were inserted near the limbus at the points perpendicular to the muscles to be operated upon (that is, at 12 and 6 o'clock for the horizontal muscle operation). Recession was done first. The conjunctiva was opened over the insertion of the muscle to be recessed. A double-armed 6-0 Vicryl suture on a fine spatulated needle was placed in a whip-stitch manner in the muscle near its insertion and locked at the sides with a double-throw knot to prevent bunching up of the muscle. The muscle was then cut, and haemostasis was achieved with diathermy. The suture was then brought through the original insertion once only. The muscle was allowed to fall back to a point of proposed recession. The suture was then secured with a double-throw knot followed by a half-bow 


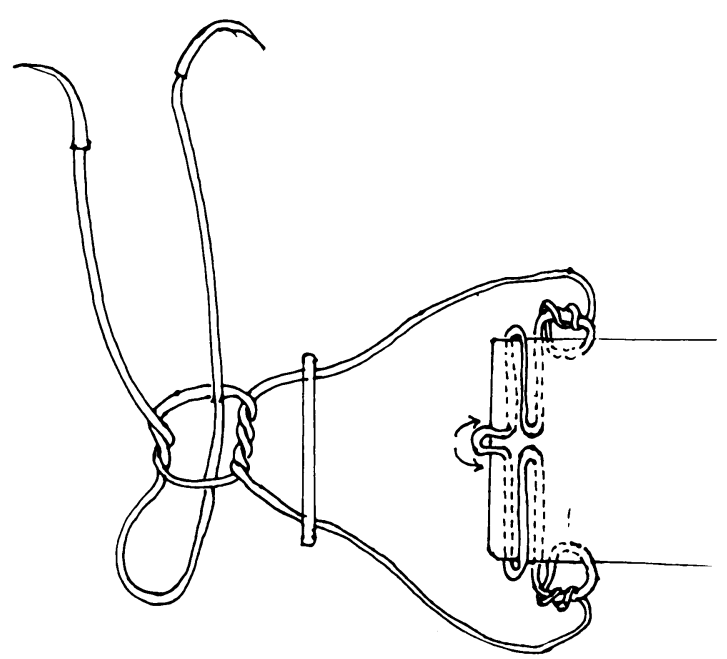

Fig. 1 Conjunctival incision over muscle insertion whip stitch in the muscle, double throw knot at sides of muscle, suture through original insertion once, and secured with a double throw followed by a half bow.
(Fig. 1). Any redundant suture was shortened.

Resection of the antagonist if indicated was done as in conventional strabismus surgery. Amethocaine $1 \%$ eyedrops was used to relieve pain whenever the patient complained on the operating table.

The patient was sat up on table after the drapes were removed. The deviation was measured for near and for distant vision by a prism cover test by an orthoptist. Any diplopia was also noted. Adjustment was made until there was no diplopia and the deviation was less than $10 \mathrm{PD}$ in the primary position, with no abnormal head posture. In cases of large deviation which could not be corrected to within 10 PD an adjustment was made until there was $25 \%$ decrease in the range of movement.

The conjunctival incision was closed and the eye was padded for one more hour.

\section{Results}

The angle of deviation after adjustment on the operating table was compared with that six weeks and
Fig. 2 Stability of adjustable suture at six weeks for near vision. Measurements in prism dioptres. Closed square $=$ preoperative exotropia with no fusion. Open square $=$ preoperative exotropia with fusion. Closed triangle = preoperative esotropia with no fusion. Open triangle= preoperative esotropia with fusion. 


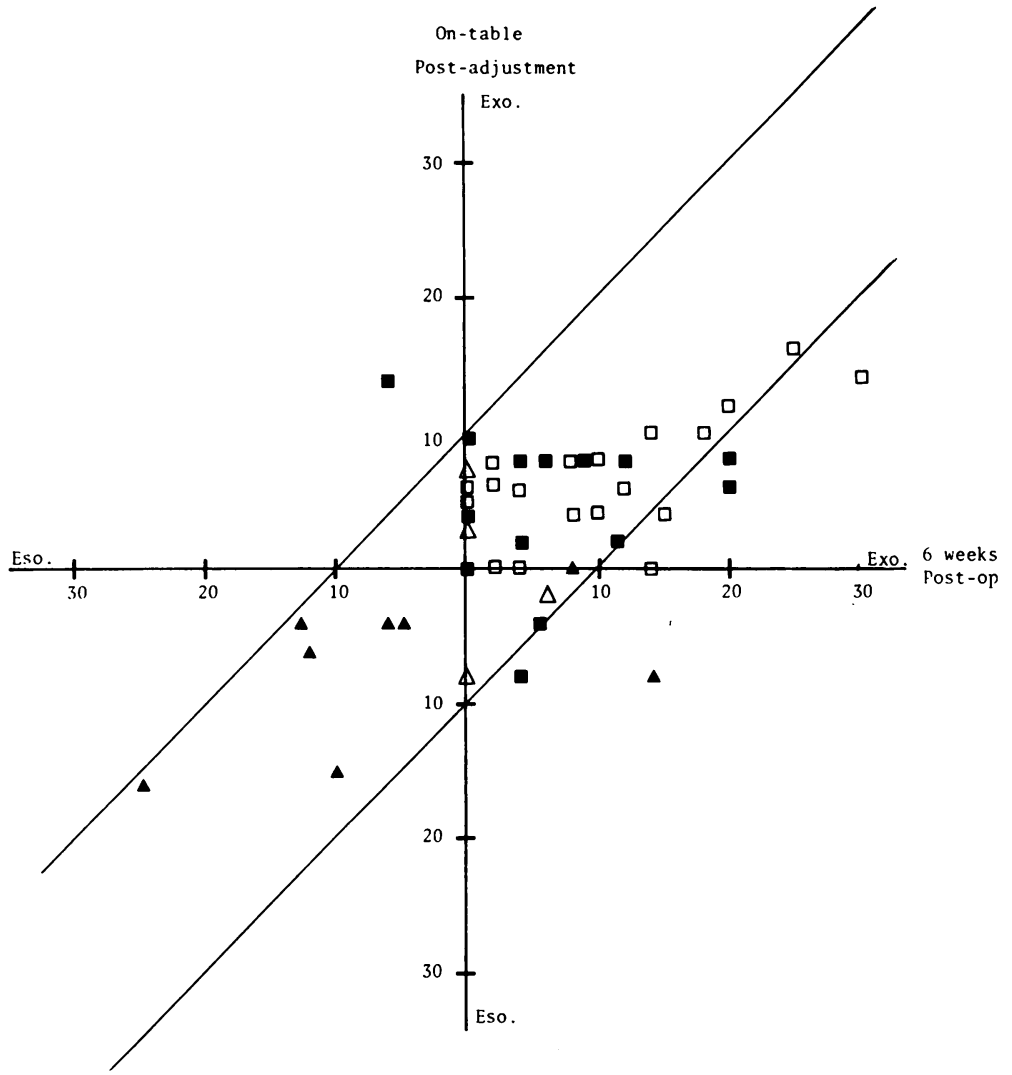

Fig. 3 Stability of adjustable suture at six weeks for distance. Measurements in prism dioptres. Symbols as in Fig. 2.

three months later and was plotted graphically (Figs. 2-5). The results are summarised in Tables 1 and 2. A change within $10 \mathrm{PD}$ was considered satisfactory.

It was found that all cases of exotropia with an angle change greater than 10 PD drifted towards the original deviation. The drift in cases of esotropia varied.

\section{Discussion}

The success of strabismus surgery is apt to be unpredictable. The behaviour of the elastic tissue and muscles is the main reason for this problem. No formula can predict the final outcome. The adjustable suture has been developed to overcome this difficulty. The operation is generally performed as a two-stage procedure. In this study it is modified to a one-stage procedure. The stability of this one-stage adjustment is what has been examined here.

For esotropia (Table 1) the mean change of deviation at six weeks was 6.75 PD for near and 5.58 PD for distant vision, which is satisfactory. At three months the mean change of deviation increased to 10.17 PD for near and 7.67 PD for distant vision.
There was one esotropic patient with a postadjustment deviation on the operating table of +4 PD that increased to +35 PD for near vision at three months after operation. Since there were only 12 esotropic patients in this study, an individual variation would cause a large change in the overall results: hence the high value for the mean change of deviation for near vision. The results for distant vision at three months are satisfactory.

For near vision 10 out of $12(83 \%)$ esotropic patients and for distance 11 out of $12(92 \%)$ esotropic patients had a change of less than 10 PD at six weeks. At three months they were eight out of $12(67 \%)$ and nine out of $12(75 \%)$ respectively.

For exotropia (Table 2) the mean change of deviation for near vision was 6.42 PD and for distant 6.79 PD at six weeks. At three months they were 7.27 PD and 7.52 PD respectively. At six weeks for both near and distant vision 26 out of 33 patients (79\%) had a change of less than 10 PD. At three months for near vision it was 25 out of $33(76 \%)$ and for distant 23 out of $33(70 \%)$. This shows that the stability of the one-stage adjustable suture is satisfactory.

A comparison between this study and the report by 


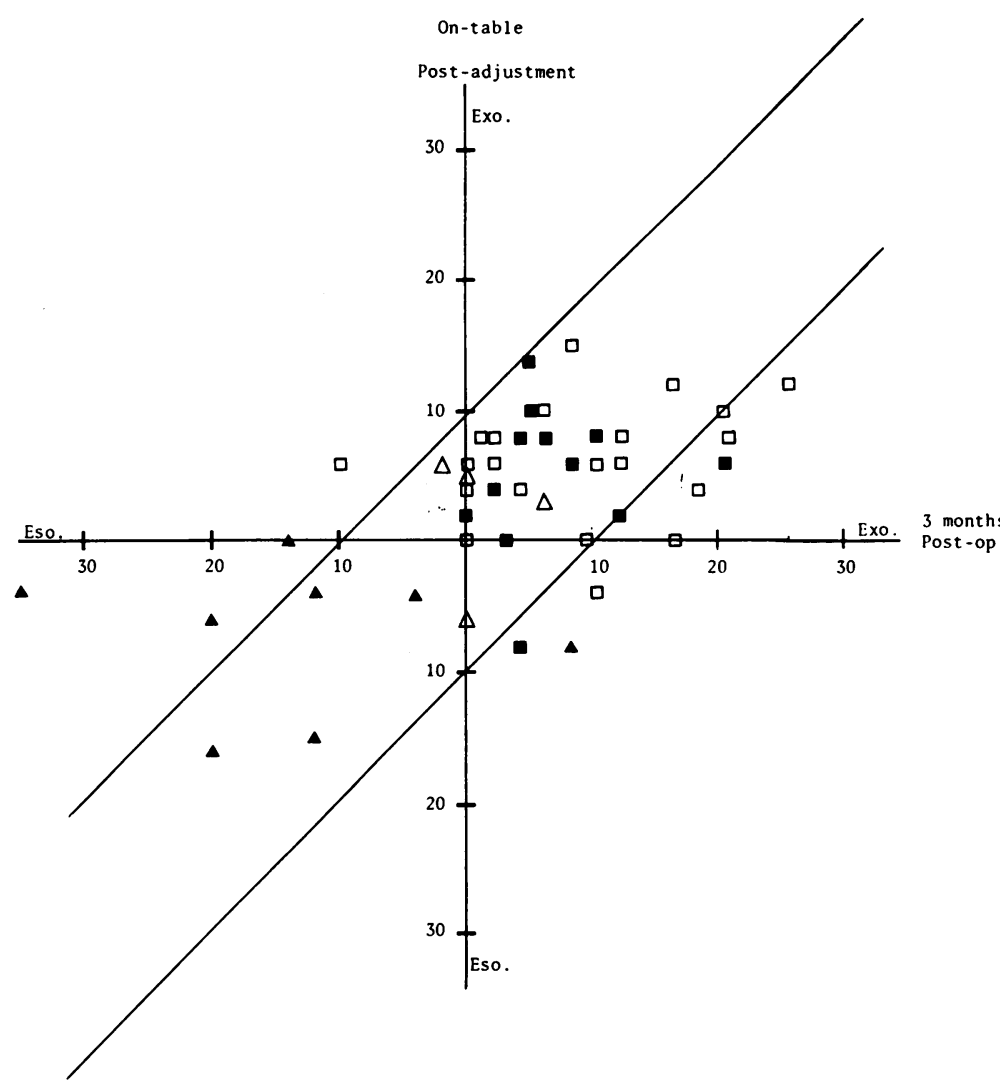

Fig. 4 Stability of adjustable suture at three months for near. Measurements in prism dioptres. Symbols as in Fig. 2.

Fig. 5 Stability of adjustable suture at three months for distance. Measurements in prism dioptres. Symbols as in Fig. 2.

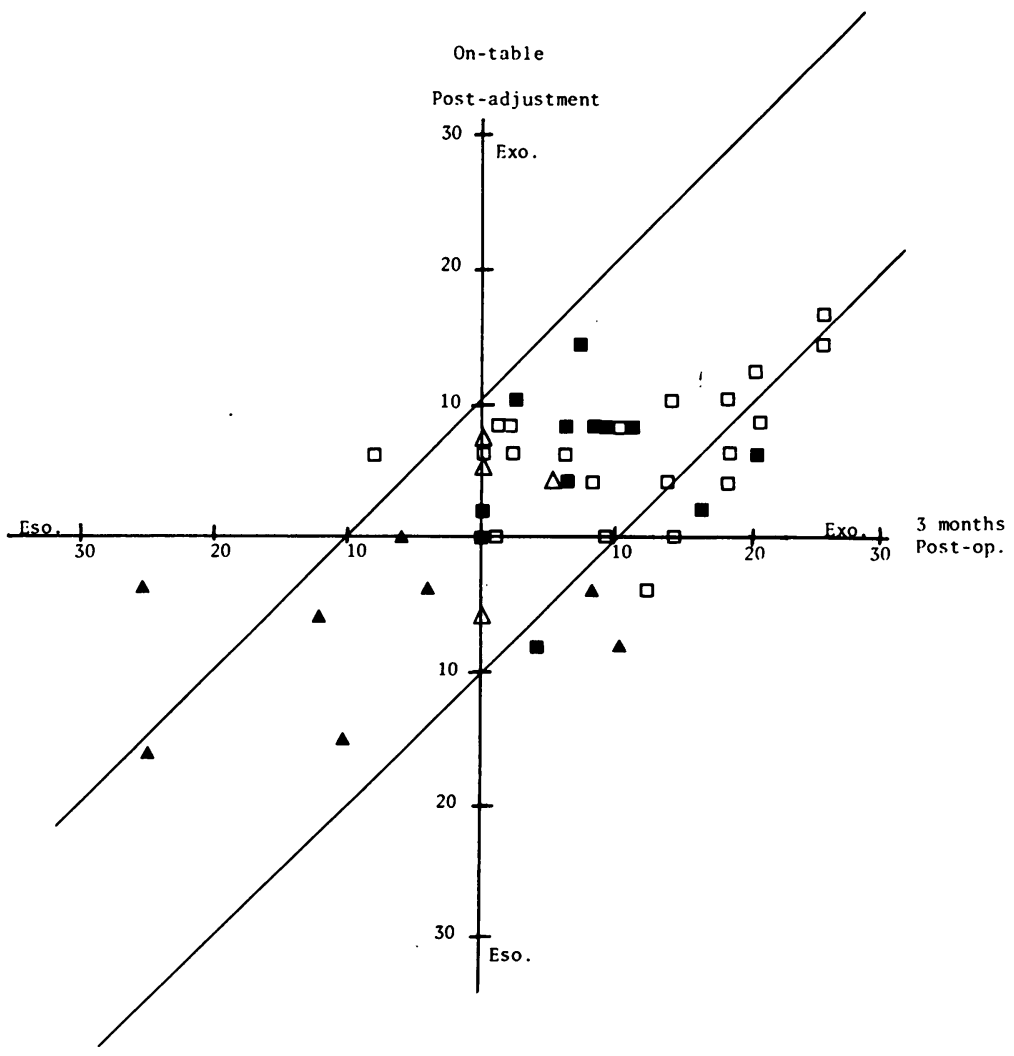


Table 1 Mean change of angle of deviation, the standard deviation, and the number of patients with an angle change of less than and greater than 10 PD for esotropia

\begin{tabular}{llllll}
\hline & \multicolumn{2}{l}{ On table to 6 weeks } & & \multicolumn{2}{l}{ On table to 3 months } \\
\cline { 2 - 3 } \cline { 5 - 6 } & Near & Distant & Near & Distant \\
\hline $\begin{array}{l}\text { Mean change of } \\
\text { deviation }\end{array}$ & $6.75 \mathrm{PD}$ & $5.58 \mathrm{PD}$ & $10 \cdot 17 \mathrm{PD}$ & $7.67 \mathrm{PD}$ \\
$\begin{array}{l}\text { SD } \\
\begin{array}{l}\text { Patients with } \\
\text { change }<10 \mathrm{PD}\end{array}\end{array}$ & 4.97 & 2.67 & 10.94 & 6.24 \\
$\begin{array}{l}\text { total patients } \\
\begin{array}{l}\text { Patients with } \\
\text { change }>10 \mathrm{PD}\end{array}\end{array}$ & $\frac{2}{12}=83.3 \%$ & $\frac{11}{12}=91.67 \%$ & $\frac{8}{12}=66 \cdot 7 \%$ & $\frac{9}{12}=75 \%$ \\
\hline \begin{tabular}{l} 
total patients \\
\hline
\end{tabular} & 12 & $\frac{1}{12}=0.83 \%$ & $\frac{4}{12}=33 \cdot 3 \%$ & $\frac{3}{12}=25 \%$ \\
\hline
\end{tabular}

Table 2 Mean change of angle of deviation, the standard deviation, and the number of patients with an angle change of less than and greater than 10 PD for exotropia

\begin{tabular}{|c|c|c|c|c|}
\hline & \multicolumn{2}{|c|}{ On table to 6 weeks } & \multicolumn{2}{|c|}{ On table to 3 months } \\
\hline & Near & Distant & Near & Distant \\
\hline $\begin{array}{l}\text { Mean change of } \\
\text { deviation }\end{array}$ & 6.42 PD & 6.79 PD & $7 \cdot 27 \mathrm{PD}$ & $7 \cdot 52 \mathrm{PD}$ \\
\hline SD & $5 \cdot 2$ & $4 \cdot 53$ & $4 \cdot 77$ & 4.96 \\
\hline $\begin{array}{l}\text { Patients with } \\
\text { change }<10 \mathrm{PD} \\
\text { total patients }\end{array}$ & $\frac{26}{33}=78 \cdot 8 \%$ & $\frac{26}{33}=78 \cdot 8 \%$ & $\frac{25}{33}=75 \cdot 8 \%$ & $\frac{23}{33}=69.7 \%$ \\
\hline $\begin{array}{l}\text { Patients with } \\
\text { change }>10 \mathrm{PD} \\
\text { total patients }\end{array}$ & $\frac{7}{33}=21 \cdot 1 \%$ & $\frac{7}{33}=21 \cdot 1 \%$ & $\frac{8}{33}=24 \cdot 4 \%$ & $\frac{10}{33}=30 \cdot 3 \%$ \\
\hline
\end{tabular}

Hamming and Kunisch-Verslype ${ }^{14}$ on the two-stage procedure is shown in Table 3 . There is no significant difference between the mean change of deviation for either near or distant vision at six weeks and three months. The ratio of patients with a change of more than 10 PD compares favourably with that of the twostage procedure. Furthermore, Olivier ${ }^{15}$ reported that 23 out of 70 patients $(33 \%)$ had a change of more than $10 \mathrm{PD}$ at six weeks after the two-stage procedure. Thus the one-stage adjustable suture is at least as stable as the usual two-stage procedure.

The one-stage adjustable suture has further advantages over the usual two-stage procedure. It saves one or more surgical procedures. General anaesthesia and its attendant risks are avoided. Admission to hospital is not absolutely necessary, and most of the patients in this study were treated as outpatients.

The significance of fusion status and original angle of deviation is analysed in Table 4 for exotropia. Apparently they have no bearing on the stability. This is consistent with the result obtained by Hamming and Kunisch-Verslype. ${ }^{14}$ In esotropia; it is inconclusive owing to the small number of patients.
Table 3 Mean change of deviation and number of patients with an angle change greater than 10 PD are compared between this study and Hamming's ${ }^{14}$

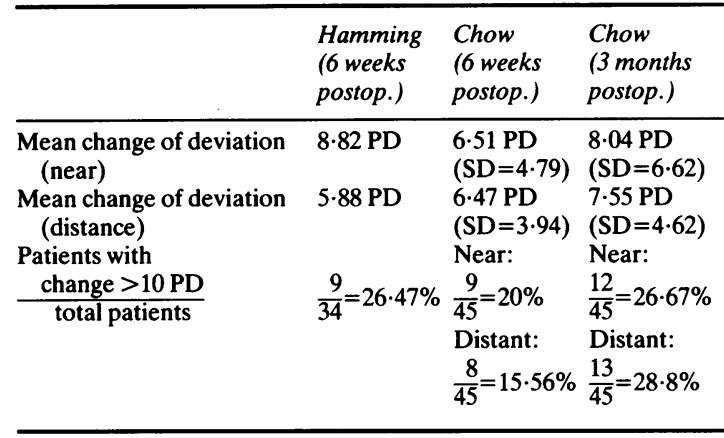

Table 4 Fusion status and mean original angle of deviation between the patients with an angle change greater than and less than 10 PD are compared for exotropia

\begin{tabular}{|c|c|c|c|}
\hline & \multicolumn{2}{|l|}{ Fusion } & \multirow{2}{*}{$\begin{array}{l}\text { Mean original angle } \\
\text { of deviation }\end{array}$} \\
\hline & Positive & Nil & \\
\hline \multicolumn{4}{|l|}{ Patients with } \\
\hline$\frac{\text { Change }<10 \mathrm{PD}}{\text { total patients }}$ & $\frac{14}{23}=61 \%$ & $\frac{9}{23}=39 \%$ & $45 \cdot 4 \mathrm{PD}$ \\
\hline $\begin{array}{l}\text { Patients with } \\
\text { change }>10 \text { PD } \\
\text { total patients }\end{array}$ & $\frac{6}{10}=60 \%$ & $\frac{4}{10}=40 \%$ & $50 \mathrm{PD}$ \\
\hline
\end{tabular}

\section{CONCLUSION}

A one-stage adjustable suture for the correction of horizontal strabismus has been found to give satisfactory stability. It is suggested that it be considered for all adult patients and some selected children so long as their condition is stable and they are cooperative. Another requirement is an experienced strabismus surgeon. The operation is particularly suitable for small deviations where only a single muscle recession is necessary.

I would like to thank Dr T K C Liu, Dr P Ho, and Dr K F So for their helpful opinions and the staff of our orthoptic unit, with special thanks to Miss F Poon for collecting the data.

\section{References}

1 Helveston EM, Ellis FD. Adjustable sutures for horizontal and vertical strabismus. Am Orthopt J 1978; 28: 18-23.

2 Jampolsky A. Current techniques of adjustable strabismus surgery. Am J Ophthalmol 1979; 88: 406-18.

3 Lennerstrand $G$. Adjustable sutures in strabismus surgery: a follow-up study. Acta Ophthalmol (Kbh) 1982; 60: 717-28.

4 Metz HS. Adjustable sutures strabismus surgery. Ann Ophthalmol 1979; 11: 1593-7. 
5 Rosenbaum AL. The use of adjustable suture procedures in strabismus surgery. Am Orthopt J 1978; 28: 88-95.

6 Rosenbaum AL, Metz HS, Carlson M, Jampolsky AJ. Adjustable rectus muscle recession surgery. A follow-up study. Arch Ophthalmol 1977; 95: 817-20.

7 Scott WE, Martin-Casals A, Jackson OD. Adjustable sutures in strabismus surgery. J Pediatr Ophthalmol Strabismus 1977; 14: $71-5$.

8 Wise J, Flanders M, Williams F, Beneish R, Goldberg LL. Adjustable sutures in strabismus surgery. Can J Ophthalmol 1982; 17: $157-60$.

9 Pittar G. Adjustable sutures for squint surgery. Aust $J$ Ophthalmol 1979; 7: 51-5.

10 Fells P. The use of adjustable sutures. Trans Ophthalmol Soc UK 1981; 101: 279-83.
11 Howard CW, Smith AG. Use of adjustable sutures. A helpful modification. Am Ophthalmol 1986: 18: 70-3.

12 Thornson TC, Jampolsky A, Scott AB. Topical anaesthesia for strabismus surgery. Ophthalmology 1966; 70: 968-72.

13 Fells P. Adjustable suture. Eye 1988; 2: 33-5.

14 Hamming NA, Kunisch-Verslype L. Surgery with adjustable sutures: postoperative measurements. Am Orthopt J 1986; 36: 93-8.

15 Olivier P, Guyen DN. Ocular alignment variations after strabismus surgery. Transactions of Fifth International the Orthoptics Congress. 99 Avenue de Saxe, 69003 Lyon, France: 1983: 523-30.

Accepted for publication 18 November 1988. 